\title{
Psychopathology: genetics and the stress-vulnerability hypothesis
}

\author{
Peter Falkai · Hans-Jürgen Möller
}

Published online: 27 March 2012

(c) The Author(s) 2012. This article is published with open access at Springerlink.com

Since the findings of dopamine blockade by antipsychotics, a dysfunction of the dopamine system has been proposed to underly psychopathological symptoms in schizophrenia. In SPECT and PET imaging studies, radioligand binding to the dopamine receptor or transporter reflects the occupancy by dopamine itself or antipsychotics. Using dual-isotope imaging for the evaluation of pre- and postsynaptic site, Schmitt et al. [1] examined striatal dopamine transporter and dopamine D2 receptor availability in first-episode schizophrenia patients and patients with haloperidol treatment compared to healthy controls. In drug-naïve patients with positive symptoms, dopamine transporter availability correlated negatively with psychopathology as did D2 receptor binding with disorganization and hallucinatory behavior, thus strengthening the dopamine hypothesis for positive symptoms. D2 receptor and dopamine transporter availability was lower in the haloperidol group which confirms previous dopamine blockade studies. However, response to antipsychotics is individual, and genetic factors may contribute to a different outcome. Mössner et al. [2] reported that patients homozygous for the risk allele ZNF804A show poorer improvement of positive symptoms compared to patients with a protective allele. Thus, identification of risk genes may help identifying patients with a different course of the disorder. A pharmacogenetic study of Crisafulli et al. [3] investigated 10 SNPs of genes related

P. Falkai $(\bowtie)$

Department of Psychiatry and Psychotherapy, University of Göttingen, Von-Siebold-Str. 5, 37075 Göttingen, Germany

e-mail: pfalkai@gwdg.de

H.-J. Möller

Department of Psychiatry and Psychotherapy,

Ludwigs-Maximililans-University Munich, Nussbaumstr. 7, 80336 Munich, Germany to pathophysiological pathways in Korean patients. They found a SNP within 5HTR1A associated with clinical improvement in both positive and negative symptoms.

In schizophrenia patients, improvement of quality of life as treatment outcome among others is dependent on support in case of problems and assistance in coping with daily life demands. Landolt et al. [4] revealed that unmet needs changing to fulfilled ones enhanced quality of life. In this context, psychosocial functioning and psychotic symptoms may be influenced by alterations of theory of mind and empathy as underlying social-cognitive deficits and possibly are heritable. In first-degree relatives of schizophrenia patients, Montag et al. [5] showed impairment in cognitive skills, suggesting that social-cognitive abilities may serve as an intermediate phenotype for schizophrenia. In a reanalysis of AMDP data by nonmetric multidimensional scaling, Läge et al. [6] replicated clusters of psychopathological symptoms in two independent samples dating from 1980 and 2003. In individual's health, the psychological well-being dimension and depressive symptoms are important variables and Morelatto de Souza and Paz Loayza Hidalgo [7] validated the WHO well-being index in a Brazilian population and showed this scale to be a useful tool for screening of depressive symptoms. Hagihara and Abe [8] highlight the influence of media reports on suicide and counteracting effects of stopping the sale of suiciderelated products in Japan.

Beside genetics, stressful experience and trauma are risk factors for the development of psychiatric diseases. Linden et al. [9] analyzed 100 case files of German servicemen during World War I and classified them in agreement with modern diagnoses. Most ancient diagnoses were "psychopathic constitution" or "hysteria." Using contemporary diagnostics, some of these soldiers had symptoms of posttraumatic stress disorder. There was a high incidence of 
pseudoseizures that highlights different human responses to traumatic experience and stress in a historical context. Stressful experiences are known to increase vulnerability to schizophrenia. Rossi et al. [10] evaluated the Community Assessment of Psychic Experiences (CAPE) in students who survived an earthquake 2009 in Italy. Unexpectedly, earth quake survivors showed lower CAPE scores than nonexposed subjects. This is in line with the hypothesis that stressful events preceding psychosis are not derived from external traumatic experiences. In a previous study, Puustinen et al. [11] reported C-reactive protein, marker of cardiovascular disease, to be associated with psychological distress. However, in a cross-sectional and 3-year followup study in Japanese male workers, Kawada [12] failed to show this relationship, which is probably due to ethnicity. Life experience, stressful events and other environmental factors are known to influence the risk of developing mental diseases. The missing link between environment and neurobiology may be explained by epigenetic mechanisms, such as DNA methylation and acetylation in disease-related brain regions. Wiers [13] refers to an fMRI study of the COMT gene with the Val allele being associated with DNA methylation [14]. She proposes the use of genetic imaging in combination with investigations of epigenetic markers in blood cells to unravel gene-environmental interactions in severe psychiatric disorders.

Open Access This article is distributed under the terms of the Creative Commons Attribution License which permits any use, distribution, and reproduction in any medium, provided the original author(s) and the source are credited.

\section{References}

1. Schmitt GJE, Dresel S, Frodl T, la Fouge 're C, Boerner R, Hahn K, Möller H-J, Meisenzahl EM (2011) Dual-isotope SPECT imaging of striatal dopamine: a comparative study between never-treated and haloperidol-treated first-episode schizophrenic patients. Eur Arch Psychiatry Clin Neurosci. doi:10.1007/s00406011-0269-4

2. Mössner R, Schuhmacher A, Wagner M, Lennertz L, Steinbrecher A, Quednow BB, Rujescu D, Rietschel M, Maier W (2011) The schizophrenia risk gene ZNF804A influences the antipsychotic response of positive schizophrenia symptoms. Eur Arch Psychiatry Clin Neurosci. doi:10.1007/s00406-011-0235-1

3. Crisafulli C, Chiesa A, Han C, Lee S-J, Park MH, Beatrice B, Andrisano C, Patkar AA, Chi-Un P, Serretti A (2011) Case- control association study for 10 genes in patients with schizophrenia: influence of 5HTR1A variation rs10042486 4 on schizophrenia and response to antipsychotics. Eur Arch Psychiatry Clin Neurosci. doi:10.1007/s00406-011-0278-3

4. Landolt K, Rössler W, Burns T, Ajdacic-Gross V, Galderisi S, Libiger J, Naber D, Derks EM, Kahn RS, Fleischhacker WW (2011) The interrelation of needs and quality of life in first-episode schizophrenia. Eur Arch Psychiatry Clin Neurosci. doi: 10.1007/s00406-011-0275-6

5. Montag C, Neuhaus K, Lehmann A, Krüger K, Dziobek I, Heekeren HR, Heinz A, Gallinat J (2011) Subtle deficits of cognitive theory of mind in unaffected first-degree relatives of schizophrenia patients. Eur Arch Psychiatry Clin Neurosci. doi: 10.1007/s00406-011-0250-2

6. Läge D, Egli S, Riedel M, Möller H-J (2011) Exploring the structure of psychopathological symptoms: a re-analysis of AMDP data by robust nonmetric multidimensional scaling. Eur Arch Psychiatry Clin Neurosci. doi:10.1007/s00406-011-0271-x

7. de Souza M, Hidalgo PL (2011) World Health Organization 5-item well-being index: validation of the Brazilian Portuguese version. Eur Arch Psychiatry Clin Neurosci. doi:10.1007/s00406011-0255-x

8. Hagihara A, Abe T (2011) Effects of media reports and the subsequent voluntary withdrawal from sale of suicide-related products on the suicide rate in Japan. Eur Arch Psychiatry Clin Neurosci. doi:10.1007/s00406-011-0279-2

9. Linden SC, Hess V, Jones E (2011) The neurological manifestations of trauma: lessons from World War I. Eur Arch Psychiatry Clin Neurosci. doi:10.1007/s00406-011-0272-9

10. Rossi A, di Tommaso S, Stratta P, Riccardi I, Daneluzzo E (2011) How much stress is needed to increase vulnerability to psychosis? a community assessment of psychic experiences (CAPE) evaluation 10 months after an earthquake in L'Aquila (Italy). Eur Arch Psychiatry Clin Neurosci. doi:10.1007/s00406-011-0258-7

11. Puustinen PJ, Koponen H, Kautiainen H, Mantyselka P, Vanhala M (2011) Psychological distress and C-reactive protein: do health behaviours and pathophysiological factors modify the association? Eur Arch Psychiatry Clin Neurosci 261:277-284

12. Kawada T (2011) Correlation between psychological distress and C-reactive protein Comment on Puustinen et al., "Psychological distress and C-reactive protein: do healthealth behaviours and pathophysiological factors modify the association?" (Eur Arch Psychi-5 atry Clin Neurosci 2011;261:277-84). Eur Arch Psychiatry Clin Neurosci. doi:10.1007/s00406-011-0276-5

13. Wiers CE (2011) Methylation and the human brain: towards a new discipline of imaging epigenetics. Eur Arch Psychiatry Clin Neurosci. doi:10.1007/s00406-011-0261-z

14. Ursini G, Bollati V, Fazio L, Porcelli A, Iacovelli L, Catalani A, Sinibaldi L, Gelao B, Romano R, Rampino A, Taurisano P, Mancini M, Di Giorgio A, Popolizio T, Baccarelli A, De Blasi A, Blasi G, Bertolino A (2011) Stress-related methylation of the catechol-O-methyltransferase Val158 allele predicts human prefrontal cognition and activity. J Neurosci 31:6692-6698 